but it clearly demonstrates that this conclusion is not immutable.

Failed vasectomies are generally categorised early or late by the time lapse from operation to observed failure and by the nature and numbers of any spermatozoa seen. This case belongs to a small subset of failures where initial sperm counts were zero and only later (in this case after the pregnancy of the man's wife) were any spermatozoa identified. Even then the spermatozoa seen were very few and all non-motile, which would normally satisfy criteria for infertility. Alderman, when seeing such sperm characteristics, would "cautiously advise" that the vasectomy had been successful. ${ }^{4}$ This is supported by Edwards and Farlowe, who observed no associated pregnancies in 200 such failures.' Schmidt disagreed and would "find it difficult to believe that these patients [showing the presence of any spermatozoa of any kind] are totally safe."

The case also shows the value of DNA profiling in

establishing beyond doubt the paternity of a child in a situation where other factors strongly suggest a different explanation. It was important that a high relative chance of paternity was obtained in this case, and the high discriminating power of the DNA systems used ensured such a figure was obtained.

We acknowledge the help of Dr T J W Kelly, consultant clinical microbiologist at the Mayday Hospital, Croydon, for his work on the semen analysis.

1 Edwards IS, Farlowe JL. Non-motile sperms persisting after vasectomy: do they matter? $B M{ }^{f} 1979 ; \mathrm{i}: 87-8$.

Philp T, Guillebaud J, Budd D. Complications of vasectomy: review of 16000 patients. Br f Urol 1984;56:745-8.

Philp T, Guillebaud J, Budd D. Late failure of vasectomy after two documented analyses showing azospermic semen. $B M F$ 1984;289:77-9.

Alderman PA. The lurking sperm: a review of failures in 8879 vasectomies performed by one physician. $\mathscr{f} A M A$ 1988;259:3142-4.

5 Schmidt SS. Vasectomy. $7 A M A$ 1988;259:3176.

(Accepted 25 Fune 1993)

\title{
General practitioners' contact with victims of suicide
}

\section{Christopher A Vassilas, H Gethin Morgan}

Department of Mental Health, University of Bristol, Bristol BS2 8DZ Christopher A Vassilas, lecturer

H Gethin Morgan, professor

Correspondence to:

Dr C A Vassilas,

Department of Old Age

Psychiatry, West Suffolk

Hospital, Bury St Edmunds, Suffolk IP33 2QZ

$B M F$ 1993;307:300-1
Concern has recently been expressed over the increase in suicide rates in young adults in the United Kingdom, ${ }^{1}$ and the Health of the Nation has now set targets for health authorities to reduce rates of suicide. ${ }^{2}$ Although we know that up to $60 \%$ of people who commit suicide consult their general practitioners during the month before their death, ${ }^{34}$ up to date information is required on the way these patients present to health care professionals. We hypothesised that those with no history of psychiatric contact and younger suicide victims would have had fewer contacts with their general practitioner than those with a psychiatric history and older victims.

\section{Methods and results}

Over 20 months the Avon coroner's records were examined, and a note was made whenever a verdict of suicide, open, or accidental death was returned on an Avon resident. Summaries of all cases with open or accidental verdicts where the death was due to the same causes as those of suicide were presented to a panel of three consultant psychiatrists. If a majority of the panel thought that the death was a suicide that case was included in the study. The general practitioner responsible for the deceased was then interviewed. For each of the subjects general practitioners provided details of a matched control selected from the practice age-sex register as the next patient of the same sex born after the suicide victim.

A total of 83 suicide victims were identified. Sixty one open and accidental deaths were judged by the panel of psychiatrists to be suicides. In one case no information on a control was obtained. No data about contact with a general practitioner were available for five subjects. One hundred and thirty nine subjects $(96 \%)$ were thus included.

Of the 107 men and 32 women in the sample, 51 were aged under 35, 45 of them men. Eighteen (35\%) of the 51 people who committed suicide under 35 years of age and $49(56 \%)$ of the 88 who were aged 35 and over had ever had psychiatric contact $\left(\chi^{2} 4 \cdot 59, \mathrm{df}=1 ; \mathrm{p}=0.03\right)$. For all time periods up to a year those who were aged over 35 years were more likely to have consulted their general practitioners than those under 35 (see table).

Similarly, in the 28 days before death 34 of the 67 $(51 \%)$ of those with a history of psychiatric contact consulted their general practitioner compared with 18 of the $72(25 \%)$ who had no history of psychiatric contact $\left(\chi^{2} 8 \cdot 76, \mathrm{df}=1, \mathrm{p}=0.003\right)$.

Numbers of suicide victims (and percentages) consulting their general practitioners before death according to age

\begin{tabular}{lccc}
\hline $\begin{array}{l}\text { Time before } \\
\text { death } \\
\text { (weeks) }\end{array}$ & $\begin{array}{c}\text { No (\%) of patients } \\
\text { aged < 35 } \\
\text { consulting GP } \\
(\mathrm{n}=51)\end{array}$ & $\begin{array}{c}\text { No (\%) of patients } \\
\text { aged } \geqslant 35 \\
\text { consulting GP } \\
(\mathrm{n}=88)\end{array}$ & $\chi^{2}(\mathrm{df}=1)$ \\
\hline 1 & $2(4)$ & $23(26)$ & $9 \cdot 35, \mathrm{p}=0.002$ \\
4 & $10(20)$ & $42(48)$ & $9 \cdot 74, \mathrm{p}=0.002$ \\
13 & $21(41)$ & $58(66)$ & $7.07, \mathrm{p}=0.008$ \\
26 & $28(55)$ & $66(75)$ & $5.07, \mathrm{p}=0.02$ \\
52 & $32(63)$ & $69(78)$ & $3 \cdot 24, \mathrm{p}=0.07$ \\
\hline
\end{tabular}

In the four weeks before death there was no difference in the proportion of people under 35 consulting their general practitioner between suicides and controls (estimated odds ratio 1.67 (95\% confidence interval 0.55 to 5.58$), p=0.45$ ). However, the patients who committed suicide when aged over 35 were significantly more likely to have consulted their general practitioner than controls (estimated odds ratio 2.67 (95\% confidence interval 1.27 to $6 \cdot 25$ ), $\mathrm{p}=0.0003$ ).

\section{Comment}

In our study the proportion of all cases of suicide among people aged under $35(37 \%)$ was nearly four times higher than that found in Bristol 30 years ago. ${ }^{3}$ Although we have confirmed earlier findings that a substantial proportion of all suicide victims do see their general practitioner before their death (in this case $36 \%$ in the 4 weeks beforehand), this is clearly not the case for those aged under 35 . The reasons for this are not clear. Among the younger victims consultation patterns were no different from those of controls, and it may be that those aged under 35 do not feel it appropriate to discuss emotional or psychological problems with a doctor. There also appears to be a greater element of impulsiveness in these suicides, with fewer harbingers.

Educational campaigns aimed at teaching general practitioners to recognise and treat depressive illness have been suggested as ways of reducing suicide rates. ${ }^{5}$ For those aged under 35 other strategies must be found, as this group does not present to general 
practitioners. Further research should be directed to finding out why this is the case.

1 Dunnel K. Deaths among 15-44 year olds. Population Trends 1991;64:38-43. 2 Secretary of State for Health. The health of the nation: a strategy for health in England. London: HMSO, 1992.
3 Seager CP, Flood RA. Suicide in Bristol. Br F Psychiatry 1965;111:919-32. 4 Barraclough B, Bunch J, Nelson B, Sainsbury P. A hundred cases of suicide: clinical aspects. $\mathrm{Br} \mathcal{F}$ Psychiatry 1974;125:355-73.

5 Rutz W, Von Knorring L, Walinder J. Long term effects of an educational program for general practitioners given by the Swedish Committee for the program for general practitioners given by the Swedish Committee for the

(Accepted 21 May 1993)

\section{Efficacy of hepatitis B vaccination: knowledge among clinical medical students}

\section{B C Oates, A J Sidebottom, S R J Maxwell}

\section{Birmingham Medical} School and Department of Medicine, Queen Elizabeth Hospital, Birmingham B15 2TH

B C Oates, medical student

A J Sidebottom, medical student

S R J Maxwell, lecturer in

clinical pharmacology

Correspondence to: Dr Maxwell.

BMf 1993;307:301
Hepatitis B virus infection is a preventable cause of morbidity and mortality. Potential complications of infection are chronic hepatitis, cirrhosis, and hepatocellular carcinoma. In 1982 the first hepatitis B vaccine was introduced into the United Kingdom. As the prevalence of hepatitis B is relatively low in the United Kingdom a selective immunisation policy has been implemented, with high risk groups identified and targeted to receive the vaccine. Doctors are a well defined group who have an increased risk of hepatitis B virus infection through contact with patients and needlestick injuries. Autoinoculation is more likely to occur early in a medical career owing to inexperience, ${ }^{1}$ so it is appropriate to immunise doctors early in their training.

We monitored the progress of the vaccination programme for medical students at Birmingham Medical School, paying particular attention to the success rate of the vaccine and the students' knowledge of its protection and their responsibility in aftercare.

\section{Subjects, methods, and results}

At Birmingham Medical School all second year preclinical medical students receive a three injection course of hepatitis B vaccine (Engerix B) in a 0,1 , and 6 month schedule. Subsequently antibody titres are measured using the Amerlite system. ${ }^{2}$ Titres above 100 $\mathrm{IU} / \mathrm{ml}$ indicate an adequate response. ${ }^{3}$ All fourth year medical students $(n=146)$ were invited to fill in a confidential questionnaire relating to their hepatitis B immunisation. It asked: $(a)$ when and where they had received the vaccination course; $(b)$ whether or not they had completed the course; (c) how long they expected the immunity they had acquired would last; (d) whether their hepatitis B antibody titre had ever been measured; and (e) if so, what the titre was. One hundred and forty six completed questionnaires were returned $(100 \%)$ and the results were analysed.

Of the 146 students, five had not completed the vaccination course. None of these five had requested antibody titres. Ninety had arranged to have their antibody titre measured after completing the course. Among these 90, 21 (23\%) had antibody titres of less than $100 \mathrm{IU} / \mathrm{ml}$ and nine $(10 \%)$ had titres of less than $=10 \mathrm{IU} / \mathrm{ml}$. A response of over $100 \mathrm{IU} / \mathrm{ml}$ was achieved in $69(77 \%)$ of the students, although only 53 of these had a record of their actual titre. Fifty two $(36 \%)$ of the 146 students surveyed believed that the immunisation schedule they had received would offer lifelong protection.

\section{Comment}

About $1 \%$ of adult inpatients carry the hepatitis B virus, so effective immunisation for health care workers is important. Although many studies have shown a greater efficacy of the hepatitis $B$ vaccine than we found among these students, ${ }^{4}$ similar results are not uncommon. ${ }^{5}$ Ideally, vaccine recipients should be aware of the need to have their immunity checked by antibody titre measurements, thus allowing booster injections to be administered if required. We found, however, that two years after completing their vaccination programme $56(38 \%)$ of the students had failed to request this investigation. This suggested that many students were unaware of the risk of vaccine failure and consequent lack of protection. Also 52 $(36 \%)$ of those surveyed assumed that immunity to hepatitis B virus after vaccination would be life long. This lack of knowledge, combined with the $23 \%$ failure rate of the vaccine, might result in a significant occupational risk over many years.

It must remain the responsibility of every individual to ensure adequate immunity both after vaccination and at regular intervals throughout a career. However, preclinical medical students, who are inexperienced and often unaware of the risk of exposure to hepatitis B virus, should be offered education and counselling.

The occupational health department at Birmingham Medical School has now adopted a new protocol for hepatitis B immunisation for preclinical medical students. In future all students will have completed the vaccination course by the end of their first year of study. They will then receive a routine call up for antibody titre measurements, allowing any booster vaccinations to be undertaken before they start their clinical course. An alternative protocol might include the use of personal record cards documenting dates of immunisations, titre measurement, and recommendations for booster injections.

This report has highlighted potential deficiencies in the management of a student hepatitis B immunisation programme. We believe that the relatively high failure rate of vaccination and limited life span of immunity deserve further recognition among medical students.

We thank Mrs Wendy Hall, occupational health nurse, for her help with this project.

\footnotetext{
1 Gilson R. Hepatitis B vaccination: Who, when and why? Prescriber 1992;3 94-100.

2 Follett EAC. Amerlite anti-HBs as an alternative method for post vaccination testing. In: Enhanced luminescence: applications for hepatitis testing. Oxford: Medicine Publishing Foundation, 1990:32-5 (symposium series 28).

3 Hadler SC, Francis DP, Maynard JE, Thompson SE, Judson FN, Echenberg $\mathrm{DF}$, et al. Long term immunogenicity and efficacy of hepatitis $\mathrm{B}$ vaccine in homosexual men. N Engl f Med 1986;315:209-14.

4 Zanetti AR, Tanzi E, Pozzi A, Romano L, Bergamini F. Yeast-derived hepatitis $B$ vaccine in dental students. A three year follow-up study. Vaccine $B$ vaccine in
$1990 ; 8: 205-8$.

5 Westmoreland D, Player V, Heap DC, Hammond A. Immunisation against hepatitis B. What can we expect? Epidemiol Infect 1990;104:499-509.
}

(Accepted 15 April 1993) 